\title{
Penerapan Metode MPE dalam Penilaian Kinerja Penyuluh Pertanian UPT BPP Sukaraja
}

\author{
Dewi Suranti, Herlina Latipa Sari \\ Jurusan Teknik Informatika, Universitas Dehasen Bengkulu \\ Jalan Meranti Raya No. 32 Kota Bengkulu \\ ${ }^{1}$ dewisuranti@unived.ac.id,
}

\begin{abstract}
In order to build qualified and reliable agricultural human resources, it is necessary for professional, creative, innovative and global oriented Agricultural Extension workers in the provision of productive, effective and efficient extension services. Agricultural Extension is directed to carry out advisory and consultation tasks for the main actors and business actors in developing their agribusiness business, so the adoption of appropriate technology can run well and in turn increase the empowerment of the main actors, productions, productivity, income and welfare of farmers and their families. The performance of agricultural extension workers can be seen in the aspects of preparation, implementation, evaluation and reporting, development of agricultural extension and agricultural extension profession profession. In addition, agricultural extension programs should be based on analysis of farmers' needs and reflect current target audience conditions. Exponential Comparison Method in appraisal of farmer extension performance at UPT BPP Sukaraja aims to know the performance of agricultural extension in conducting counseling at UPT BPP Sukaraja. This is due to the lack of extension workers in BP3K Sukaraja. The results of the resulting assessment in the form of work performance ranking of each extension worker. Based on the result of the calculation methods show performance rankings. With this is expected to make it easy for UPT BPP sukaraja in carrying out routine performance appraisal performance of extension workers who had been a constraint in conducting appraisal performance extension. Agricultural extension workers can carry out their duties and responsibilities
\end{abstract}

Keywords - Appraisal of Agricultural Extensionist, MPE, UPT BPP Sukaraja

\section{Pendahuluan}

Kinerja penyuluh pertanian yang baik merupakan dambaan setiap stakeholder pertanian. Kinerja penyuluh pertanian secara garis besarnya dapat dilihat pada aspek persiapan, pelaksanaan, evaluasi dan pelaporan, pengembangan penyuluhan pertanian dan pengembangan profesi penyuluh pertanian. Selain itu, aspek kepemimpinan, komunikasi, kemitraan usaha dan diseminasi teknologi serta penguasaan terhadap bidang teknis keahlian juga sangat menentukan tingkat keberhasilan seorang penyuluh. Kinerja penyuluh pertanian pada aspek persiapan, pelaksanaan, evaluasi dan pelaporan merupakan suatu rangkaian yang tersistematis dan terstruktur dalam suatu alur yang tak terpisahkan. Program penyuluhan pertanian harus berlandaskan pada analisis kebutuhan petani dan mencerminkan kondisi khalayak sasaran saat ini dan kondisi khalayak sasaran yang akan diwujudkan[5].

UPT BPP Sukaraja berupayakan untuk peningkatan kinerja penyuluh sebab dikhawatirkan akan berdampak negatif terhadap pembangunan pertanian. Menurut Kepala UPT Dinas Ketahanan Pangan Kecamatan Sukaraja Kabupaten Seluma masih tergolong kekurangan tenaga penyuluh pertanian saat ini. Oleh karena itu diperlukan suatu penelitian untuk mengetahui sejauh mana kinerja penyuluh pertanian yang ada di Kabupaten Seluma khususnya di UPT BPP Sukaraja saat ini. Dengan mengetahui kinerja penyuluh pertanian ini diharapkan akan dapat disusun langkah pembinaan yang lebih terarah terhadap penyuluh pertanian sehingga kegiatan penyuluhan pertanian ke depan dapat dilaksanakan secara lebih tepat guna dan berhasilguna.

Salah satu metode yang digunakan dalam penilaian kinerja penyuluh pertanian adalah menggunakan Metode Perbandingan Eksponential (MPE) [6]. Dengan kedua metode ini diharapkan dapat diterapkan dalam penilaian kinerja penyuluh pertanian untuk perengkingan untuk setiap alternatif

Metode perbandingan eksponential (MPE) merupakan metode skoring terhadap pilihan yang ada, perbedaan nilai antar kriteria dapat dibedakan tergantung kepada kemampuan orang yang menilai yang mampu untuk menentukan urutan prioritas alternative keputusan dengan menggunakan beberapa kriteria. Untuk nilai skor yang dihasilkan akan menggambarkan urutan prioritas yang menjadi besar, ini mengakibatkan urutan prioritas alternative keputusan menjadi lebih nyata [6].

Perumusan masalah dari penelitian ini adalah sebagai berikut:

1. Bagaimana menerapkan Metode Perbandingan Eksponential dalam Penilaian Kinerja Penyuluh pertanian?

\section{LANDASAN TEORI}

\section{A. Perbandingan Eksponential (MPE)}

Menurut [6] MPE mampu mengurangi bias yang mungkin terjadi dalam analisis. Untuk nilai skor yang dihasilkan akan menggambarkan urutan prioritas yang menjadi besar, ini mengakibatkan urutan prioritas alternatif 
keputusan menjadi lebih nyata dan merupakan metode skoring terhadap pilihan yang ada. Dengan ini nilai antar criteria dapat dibedakan tergantung kepada kemampuan orang yang menilai.

Langkah-langkah dalam menentukan metode MPE :

1. Menyusun alternatif-alternatif keputusan yang akan dipilih.

2. Menentukan kriteria atau perbandingan keputusan yang penting untuk dievaluasi

3. Menentukan tingkat kepentingan dari setiap kriteria keputusan

4. Melakukan penilaian terhadap semua alternatif pada setiap kriteria

5. Menghitung skor atau nilai total setiap alternatif

6. Menentukan urutan prioritas keputusan didasarkan pada skor atau nilai total masing-masing alternatif.

Formulasi perhitungan skor untuk setiap alternatif adalah terlihat pada persamaan 3 :

Total Nilai $\left(\mathrm{TN}_{\mathrm{i}}\right)=\sum_{\boldsymbol{d}_{\mathfrak{l}=\mathbb{1}}}^{\mathrm{m}}\left(\text { RKij }^{\mathrm{m}}\right)^{\mathrm{TKK}}{ }_{\mathrm{j}}$

Dimana :

$\mathrm{TN}_{\mathrm{i}}=$ Total nilai alternatif $\mathrm{ke}-\mathrm{i}$

$\mathrm{RK}_{\mathrm{ij}} \quad=$ Derajat kepentingan relatif kriteria ke-j pada pilihan keputusan $\mathrm{i}$

$\mathrm{TKK}_{\mathrm{j}}=$ derajat kepentingan criteria keputusan ke-j; $\mathrm{TKK}_{\mathrm{j}}>0$; Bil bulat

$\mathrm{M} \quad=$ jumlah criteria keputusan

$\mathrm{N} \quad=$ jumlah pilihan keputusan

$\mathrm{j} \quad=1,2,3, \ldots \mathrm{m}=$ jumlah kriteria

$\mathrm{i} \quad=1,2,3, \ldots \mathrm{n}=$ jumlah pilihan alternative

\section{B. Kinerja}

Kinerja merupakan prestasi yang dicapai karyawan dalam melaksanakan suatu pekerjaan dalam suatu organisasi.Agar dapat memberikan umpan balik karyawan maupun organisasi, maka perlu dilakukan penilaian atas prestasi tersebut.Sedangkan pegertian tentang prestasi kerja (job performance) ialah successful role achievement yang diperoleh seseorang dari perbuatannya.Prestasi berarti merupakan pencapaian hasil kerja. Pegawai yang kinerjanya tinggi akan produktif dalam bekerja. Hal itu menunjukkan bahwa kinerja sangat erat hubungannya dengan produktivitas [4].

\section{Penyuluh Pertanian}

Menurut [1] Penyuluh pertanian adalah pemandu yang memandu kliennya untuk menemukan ilmu dan teknologi yang mereka butuhkan untuk memecahkan masalah mereka sendiri, dalam proses pemanduan ini petani bukan lagi sebagai murid tetapi sebagai mitra belajar yang melakukan proses belajar. Para pendamping dalam hal ini penyuluh, diharapkan dapat bertugas membantu kelompok-kelompok masyarakat dalam menyelenggarakan usaha dan pengorganisasian kelompok.
Di dalam Undang-undang nomor 16 tahun 2006 tidak dijelaskan secara eksplisit mengenai tugas seorang penyuluh. Pada undang-undang tersebut hanya disebutkan mengenai tugas lembaga-lembaga yang secara langsung menangani sistem penyuluhan dari tingkat pusat sampai ke desa. Tugas seorang penyuluh pertanian tercermin dari kegiatan penyuluh yang digariskan pada Peraturan Menteri Pendayagunaan Aparatur Negara nomor: Per/02 /Menpan/2/2008 tentang Jabatan Fungsional Penyuluh Pertanian dan Angka Kreditnya. Berdasarkan keputusan tersebut kegiatan penyuluh pertanian dibedakan berdasarkan kelompok penyuluh yaitu penyuluh terampil dan ahli [2].

\section{Kinerja Penyuluh Pertanian}

Kinerja [7] merupakan tingkat keberhasilan dalam melaksanakan tugas serta kemampuan untuk mencapai tujuan yang telah ditetapkan. Kinerja dinyatakan baik dan sukses jika yang diiginkan dapat tercapai dengan baik. Ada beberapa karakteristik indikator kinerja penyuluh yaitu kunjungan kerja setiap bulan ke wilayah desa binaan, adanya program kerja yang dibuat setiap kunjungan kerja ke desa binaan, adanya laporan kegiatan yang dilakukan setiap bulannya, kedisiplinan, materi penyuluhan dan metode yang digunakan dalam penyuluhan.

\section{METODOLOGI}

\section{A. Teknik Pengumpulan Data}

Teknik pengumpulan data yang digunakan dalam penelitian ini adalah sebagai berikut :

1. Observasi yaitu pengumpulan data dengan melakukan pengamatan langsung dilapangan untuk memperoleh data yang berkaitan dengan objek penelitian.

2. Wawancara yaitu pengumpulan data dengan melakukan wawancara langsung dengan pihak-pihak yang terkait untuk memperoleh informasi sehubungan dengan penelitian.

3. Kuesioner yaitu alat yang digunakan dalam bentuk pertanyaan tertulis yang diberikan kepada responden pada saat wawancara yang berfungsi sebagai komponen utama dalam memperoleh data yang sesuai dengan keperluan penelitian.

4. FGD (Focus Group Discussion) untuk mendapatkan gambaran awal dari peta permasalahan yang ada.

\section{B. Kerangka Pikir}

Kerangka penilaian kinerja penyuluh pertanian di UPT BPP Sukaraja yang menjadi objek penelitian adalah penyuluh, dapat dilihat pada Gambar 1 . 
Tabel 1. Kriteria Penilaian Kinerja Penyuluh Pertanian

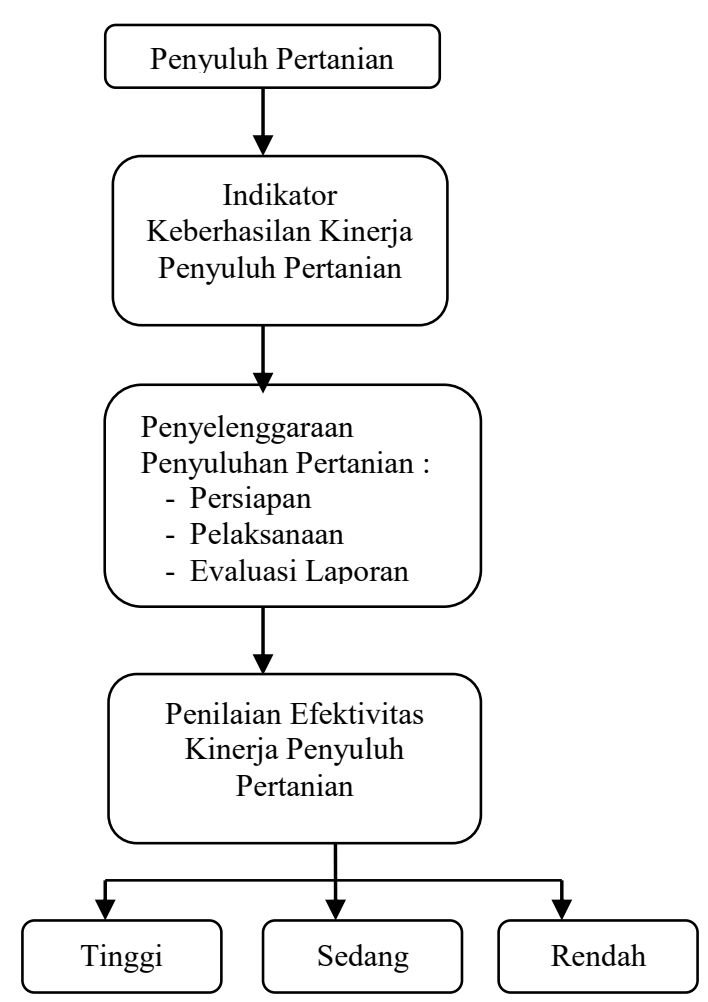

Gambar 1 Skema Kerangka pikir Kinerja Penyuluh Pertanian

\section{Metode Analisis}

Data primer dikumpulkan secara langsung dengan menggunakan alat kuesioner yang telah dibuat terlebih dahulu dan memuat pertanyaan-pertanyaan yang dibutuhkan berdasarkan tujuan yang akan dicapai. Data yang diperoleh selanjutnya diolah, ditabulasi dan dianalisis.

Analisis data yang digunakan dalam penelitian ini adalah dengan menerapakan Metode MPE. Adapun indikator penilaiannya yaitu garis besar kegiatan penyuluhan, dan indikator keberhasilan penyuluh pertanian yang ditetapkan departemen pertanian antara lain :

1. Persiapan Penyuluhan Pertanian

2. Pelaksanaan Penyuluh Pertanian

3. Evaluasi Pelaporan

\section{Penerapan Metode Perbandingan Eksponential (MPE)}

Menerapan Simple Additive Wighted dan Perbandingan Eksponential dalam penilaian kinerja penyuluh pertanian di UPT BPP Sukaraja, terdapat 16 (enam belas) kriteria yang diajukan dalam pengambilan keputusan sesuai dengan Permentan, 2013 dapat dilihat pada Tabel 1:

\begin{tabular}{|c|c|}
\hline $\begin{array}{c}\text { Kode } \\
\text { Kriterian }\end{array}$ & Kriteria \\
\hline $\mathrm{C}_{\mathrm{I}}$ & $\begin{array}{l}\text { Membuat data potensi wilayah dan agro } \\
\text { ekosistem }\end{array}$ \\
\hline $\mathrm{C}_{2}$ & $\begin{array}{l}\text { Memandu (pengawalan dan pendampingan ) } \\
\text { penyususnan RDKK }\end{array}$ \\
\hline $\mathrm{C}_{3}$ & $\begin{array}{l}\text { Penyususnan programa penyuluh pertanian desa } \\
\text { dan kecamatan }\end{array}$ \\
\hline $\mathrm{C}_{4}$ & $\begin{array}{l}\text { Membuat rencanan kerja tahunan Penyuluh } \\
\text { Pertanian }\end{array}$ \\
\hline $\mathrm{C}_{5}$ & $\begin{array}{l}\text { Melaksanakan deseminasi/penyebaran materi } \\
\text { penyuluhah }\end{array}$ \\
\hline $\mathrm{C}_{6}$ & $\begin{array}{l}\text { Melaksanakan penerapan metode penyuluhan } \\
\text { pertanian dalam bentuk kunjungan }\end{array}$ \\
\hline $\mathrm{C}_{7}$ & $\begin{array}{l}\text { Melaksanakan penrapan metode penyuluhahn } \\
\text { dalam bentuk demontrasi }\end{array}$ \\
\hline $\mathrm{C}_{8}$ & $\begin{array}{l}\text { Melaksanakan penerapan metode penyuluhan } \\
\text { dalam bentuk temu-temu }\end{array}$ \\
\hline $\mathrm{C}_{9}$ & $\begin{array}{l}\text { Melaksanakan penerapan metode penyuluhan } \\
\text { dalam bentuk kursus }\end{array}$ \\
\hline $\mathrm{C}_{10}$ & $\begin{array}{l}\text { Melaksanakan peningkatan kapasitas petani } \\
\text { terhadap akses informasi }\end{array}$ \\
\hline $\mathrm{C}_{11}$ & $\begin{array}{l}\text { Menumbuhkan kelompok tani/gapoktan dari } \\
\text { aspek kualitas dan kuantitas }\end{array}$ \\
\hline $\mathrm{C}_{12}$ & $\begin{array}{l}\text { Meningkatkan kelas kelompok tani dari aspek } \\
\text { kuantitas dan aspek kualitas }\end{array}$ \\
\hline $\mathrm{C}_{13}$ & $\begin{array}{l}\text { Menumbuhkan dan mengembangkan } \\
\text { kelembagaan ekonomi petani dari aspek jumlah }\end{array}$ \\
\hline $\mathrm{C}_{14}$ & $\begin{array}{l}\text { Meningkatnya produksi komoditi unggulan di } \\
\text { WKPP dibandingkan produksi sebelumnya }\end{array}$ \\
\hline $\mathrm{C}_{15}$ & $\begin{array}{l}\text { Melakukan evaluasi pelaksaaan penyuluhan } \\
\text { pertanian }\end{array}$ \\
\hline $\mathrm{C}_{16}$ & $\begin{array}{l}\text { Membuat Laporan Pelaksanaan Penyuluhaan } \\
\text { pertanian }\end{array}$ \\
\hline
\end{tabular}

Dari kriteria tersebut, maka dibuat suatu tingkat kepentingan kriteria berdasarkan bobot yang telah ditentukan kedalam bilangan fuzzy. Rating kecocokan setiap alternatif seperti terlihat pada Tabel 2:

TABEL 2. Bobot Kriteria

\begin{tabular}{cl}
\hline Bobot & \multicolumn{1}{c}{ Nilai Bobot } \\
\hline 5 & Sangat Tinggi \\
4 & Tinggi \\
3 & Cukup \\
2 & Rendah \\
1 & Sangat Rendah \\
\hline
\end{tabular}

\section{Penerapan Metode Perbandingan Eksponential (MPE)}

Implementasi perbandingan Eksponential untuk penilaian kinerja penyuluh pertanian diambil contoh 5 data penyuluh pertanian dengan memiliki nilai kriteria seperti pada Tabel 3 dan nilai kuantatif terlihat Tabel 4. 
Tabel III. Bobot ( nilai kuantatif)

\begin{tabular}{cl}
\hline Bobot & \multicolumn{1}{c}{ Nilai } \\
\hline 1 & Kurang penting bobot \\
2 & Standar dengan bobot \\
3 & Cukup penting bobot \\
4 & Penting dengan bobot \\
5 & Sangat Penting bobot \\
\hline
\end{tabular}

Tabel 4. Nilai Alternatif

\begin{tabular}{lllllllllll}
\hline & \multicolumn{1}{c}{ Kriteria } \\
\cline { 2 - 11 } \multicolumn{1}{c}{} & $\mathbf{C}$ & $\mathbf{C}$ & $\mathbf{C}$ & $\mathbf{C}$ & $\mathbf{C}$ & $\mathbf{C}$ & $\mathbf{C}$ & $\mathbf{C}$ & $\mathbf{C}$ & $\mathbf{C}$ \\
& $\mathbf{1}$ & $\mathbf{2}$ & $\mathbf{3}$ & $\mathbf{4}$ & $\mathbf{5}$ & $\mathbf{6}$ & $\mathbf{7}$ & $\mathbf{8}$ & $\mathbf{9}$ & $\mathbf{1 0}$ \\
\hline Sirajudin & 5 & 4 & 3 & 4 & 2 & 3 & 5 & 5 & 3 & 5 \\
Nasir Lubis & 5 & 3 & 3 & 3 & 2 & 3 & 5 & 5 & 3 & 3 \\
Sudirman & 5 & 5 & 4 & 3 & 4 & 3 & 5 & 5 & 5 & 3 \\
Sugianto & 3 & 4 & 4 & 4 & 3 & 4 & 3 & 5 & 5 & 4 \\
Eko Susanto & 3 & 2 & 4 & 2 & 3 & 2 & 5 & 5 & 3 & 2 \\
\hline
\end{tabular}

Tabel 4. Lanjutan Nilai Alternatif

\begin{tabular}{lcccccc}
\hline \multirow{2}{*}{ Alternatif } & \multicolumn{7}{c}{ Kriteria } \\
\cline { 2 - 7 } & $\mathbf{C}_{\mathbf{1 1}}$ & $\mathbf{C}_{\mathbf{1 2}}$ & $\mathbf{C}_{\mathbf{1 3}}$ & $\mathbf{C}_{\mathbf{1 4}}$ & $\mathbf{C}_{\mathbf{1 5}}$ & $\mathbf{C}_{\mathbf{1 6}}$ \\
\hline Sirajudin & 3 & 2 & 4 & 3 & 4 & 4 \\
Nasir Lubis & 4 & 3 & 2 & 3 & 3 & 3 \\
Sudirman & 4 & 3 & 4 & 3 & 3 & 4 \\
Sugianto & 4 & 4 & 2 & 2 & 3 & 3 \\
Eko Susanto & 3 & 2 & 3 & 2 & 3 & 3 \\
\hline
\end{tabular}

Adapun bobot kepentingan untuk masing-masing kriteria dapat dilihat pada tabel 5 .

Tabel 5. Bobot Kepentingan

\begin{tabular}{|c|c|c|c|}
\hline Kode Kriterian & Kriteria & $\begin{array}{c}\text { Kode } \\
\text { Kriterian }\end{array}$ & Kriteria \\
\hline $\mathrm{C}_{\mathrm{I}}$ & 5 & $\mathrm{C}_{9}$ & 5 \\
\hline $\mathrm{C}_{2}$ & 5 & $\mathrm{C}_{10}$ & 5 \\
\hline $\mathrm{C}_{3}$ & 5 & $\mathrm{C}_{11}$ & 5 \\
\hline $\mathrm{C}_{4}$ & 5 & $\mathrm{C}_{12}$ & 5 \\
\hline $\mathrm{C}_{5}$ & 5 & $\mathrm{C}_{13}$ & 5 \\
\hline $\mathrm{C}_{6}$ & 5 & $\mathrm{C}_{14}$ & 5 \\
\hline $\mathrm{C}_{7}$ & 5 & $\mathrm{C}_{15}$ & 5 \\
\hline $\mathrm{C}_{8}$ & 5 & $\mathrm{C}_{16}$ & 5 \\
\hline
\end{tabular}

Langkah berikutnya melakukan penilaian terhadap semua alternative pada setiap kriteria dengan menggunakan rumus MPE.

\footnotetext{
Sirajudin $=5^{\wedge} 5+4^{\wedge} 5+3^{\wedge} 5+4^{\wedge} 5+2^{\wedge} 5+3^{\wedge} 5+5^{\wedge} 5+5^{\wedge} 5+3^{\wedge} 5$ $+5^{\wedge} 5+3^{\wedge} 5+2^{\wedge} 5+4^{\wedge} 5+3^{\wedge} 5+4^{\wedge} 5+4^{\wedge} 5$

Nasir Lubis $=5^{\wedge} 5+3^{\wedge} 5+3^{\wedge} 5+3^{\wedge} 5+2^{\wedge} 5+3^{\wedge} 5+5^{\wedge} 5+5^{\wedge} 5+3^{\wedge} 5+$ $3^{\wedge} 5+4^{\wedge} 5+3^{\wedge} 5+2^{\wedge} 5+3^{\wedge} 5+3^{\wedge} 5+3^{\wedge} 5$

Sudirman $=5^{\wedge} 5+5^{\wedge} 5+4^{\wedge} 5+3^{\wedge} 5+4^{\wedge} 5+3^{\wedge} 5+5^{\wedge} 5+5^{\wedge} 5+5^{\wedge} 5+$ $3^{\wedge} 5+4^{\wedge} 5+3^{\wedge} 5+4^{\wedge} 5+3^{\wedge} 5+3^{\wedge} 5+4^{\wedge} 5$

Sugianto $=3^{\wedge} 5+4^{\wedge} 5+4^{\wedge} 5+4^{\wedge} 5+3^{\wedge} 5+4^{\wedge} 5+3^{\wedge} 5+6^{\wedge} 5+6^{\wedge} 5+$
}

$4^{\wedge} 5+4^{\wedge} 5+4^{\wedge} 5+2^{\wedge} 5+2^{\wedge} 5+3^{\wedge} 5+3^{\wedge} 5$

Eko Susanto $=3^{\wedge} 5+2^{\wedge} 5+4^{\wedge} 5+2^{\wedge} 5+3^{\wedge} 5+2^{\wedge} 5+5^{\wedge} 5+5^{\wedge} 5+3^{\wedge} 5+$ $2^{\wedge} 5+3^{\wedge} 5+2^{\wedge} 5+3^{\wedge} 5+2^{\wedge} 5+3^{\wedge} 5+3^{\wedge} 5$

Menghitung skor atau nilai total setiap alternatif. Hasil perhitungan dapat dilihat pada Tabel 6 .

Tabel 6.

Hasil Perhitungan Skor MPE untuk setiap Alternatif

\begin{tabular}{lcccccc}
\hline \multirow{2}{*}{ Alternatif } & \multicolumn{5}{c}{ Kriteria } & \multirow{2}{*}{ NP } \\
\cline { 2 - 6 } & $\mathbf{C}_{\mathbf{1}}$ & $\mathbf{C}_{\mathbf{2}}$ & $\mathbf{C}_{\mathbf{n}}$ & $\mathbf{C}_{\mathbf{1 5}}$ & $\mathbf{C}_{\mathbf{1 6}}$ & \\
\hline Sirajudin & 3125 & 1024 & $\ldots$ & 1024 & 1024 & 18899 \\
Nasir Lubis & 3125 & 243 & $\ldots$ & 243 & 243 & 12893 \\
Sudirman & 3125 & 3125 & $\ldots$ & 243 & 1024 & 22203 \\
Sugianto & 243 & 1024 & $\ldots$ & 243 & 243 & 14697 \\
Eko Susanto & 243 & 32 & $\ldots$ & 243 & 243 & 9167 \\
\hline
\end{tabular}

Setelah hasil perhitungan skor MPE didapat untuk setiap alternative maka selanjutnya menentukan prioritas keputusan didasarkan pada total nilai masing alternative berdasarkan nilai tertinggi, yang dapat dilihat pada Tabel 7.

Tabel 7. Hasil Perangkingan

\begin{tabular}{lcc}
\hline \multicolumn{1}{c}{ Penyuluh } & $\begin{array}{c}\text { Nilai Keputusan } \\
\text { MPE }\end{array}$ & Rangking \\
\hline Sudirman & 22203 & 1 \\
Sirajudin & 18899 & 2 \\
Sugianto & 14697 & 3 \\
Nasir Lubis & 12893 & 4 \\
Eko Susanto & 9167 & 5 \\
\hline
\end{tabular}

Berdasarkan penilaian kinerja penyuluh menggunakan metode Perbandingan Eksponential maka diperoleh hasil seperti pada Tabel VII. Maka dapat dilihat nilai terbesar adalah yang bernama Sudirman sebagai penyuluh yang memiliki kinerja lebih baik.

\section{KESIMPULAN}

Hasil analisa penerapan metode Metode Perbandingan Eksponential (MPE) dalam penilaian kinerja penyuluh pertanian pada UPT BPP Sukaraja memberikan hasil bahwa metode yang diterapkan mendapat perhitungan akhir penilaian kinerja penyuluh pertanian dengan hasil menghasilkan rangking kinerja penyuluh yang sesuai berdasarkan pengujian yang telah dilakukan. Berdasarkan dari penelitian ini dapat dibangun dan dikembangkan sebuah software yang dapat membantu dalam penghitungan metode lain agar mendapatkan hasil yang lebih cepat dan akurat. 


\section{Terima KASIH}

Unit Pelaksana Teknis Balai Penyuluh Pertanian Sukaraja

\section{DAFTAR PUSTAKa}

[1] Anonim, "Kompetensi Penyuluh dalam Pengembangkan Modal Usaha Kecil di Bidang Pertanian" http://respository.ipb.ac.id. Diakses pada tanggal 10 Maret 2015.Bengkulu. 2006.

[2] Jamal. 2011. Laporan Penelitian Efektivitas Kerja Penyuluh PertanianLapangan.http://litbangjambi11.files.wordpress.com/2011/0 7/laporan-akhir-efektivitas-kerja-ppl3.pdf. Diakses pada tanggal 09 Maret 2016. Bengkulu.

[3] Marimin, "Teknik dan Aplikasi Pengambilan Keputusan Kriteria Majemuk", Grasindo, 2004

[4] Peraturan Menteri Pertanian Nomor 91/Permentan/OT.140/9/201

[5] Sapar, Lanteng, B. 2017. Faktor-Faktor yang Mempengaruhi Kinerja Penyuluh Pertanian dalam Peningkatan Produktivitas Kakao di Kota Palopo. Jurnal Ekonomi Pembangunan. Vol. 3(1).

[6] Sari Febrina, "Metode dalam Pengambilan Keputusan", Deepublish, 2017

[7] Widayanto. 2010. "Kompetensi dan Kinerja Penyuluh Pertanian Pada Badan Pelaksana Penyuluhan Pertanian, Perikanan dan Kehutanan Kota Kendari. 